\title{
AS ALTERAÇÕES ELETROCARDIOGRÁFICAS NOS PROCESSOS CORONARIANOS (*)
}

\author{
Acadêmico MATHEUS M. ROMEIRO NETO \\ Acadêmico DOMINGOS A. LOMONACO
}

Internos voluntários da 2.a M. H. da Santa Casa - Serviço do Prof. Rubiāo Meira (3.a Clínica Médica da Faculdade de Medicina da Universidade de Sāo Paulo).

$\mathrm{E}^{\prime}$ inegavel que, nestes últimos anos, tem aumentado notavelmente a frequência dos casos registrados de enfarte do miocárdiò.

Para alguns autores, a explicação estaria no fato de se ter tornado mais agitada a vida moderna; o dinamismo da época atual, acentuando cada vez mais a luta pela vida, deve, sem dúvida, acarretar alguma repercussão sobre as coronárias.

Entretanto, se não se deve afastar imediatamente esse fator, tambem não se deve considerá-lo como único; ao contrário, segundo a opinião mais corrente, à qual filiamos a nossa, deve-se explicar o aumento do número de casos, em virtude de dispormos, atualmente, de meios diagnósticos mais exatos.

Com efeito, nem sempre o enfarte do miocárdio se revela pelos sintomas clássicos; são numerosos os casos de pacientes com perturbações coronarianas sem dor, nem hipotonia, etc. Dentre os exames đe que podemos lançar mão, ressalta o notavel alcance do eletrocardiograma: 'os sinais são dotados de tal grau de exatidão, que bastaria a sua aplicação no enfarte do miocárdio para assegurar a sua enorme importância, como exame subsidiário de prestígio indiscutivel.

Tendo em conta tudo isso é que fomos levados a condensar em modesto trabalho a descrição sumária dos sinais mais característicos, focalizados com precisão nestes últimos anos, em casos de perturbações da circulação coronária.

$\mathrm{Na}$ confecçã̃o do presente trabalho, fizemos uso de traçados da coleção do $\mathrm{d}$ r. Luiz V. Décourt, livre docente da cadeira de Clínica Médica da nossa Faculdade. Aproveitamos o ensejo que se nos apresenta para ficar consignado aqui o nosso profundo agradecimento ao jovem mestre, mormente pela sábia orientação que nos prestou.

Analisaremos, no início, mais rapidamente, o eletrocardiograma nas insuficiências coronarianas, em geral e, depois, com maior minúcia, o enfarte do miocárdio.

(*). Trabalho apresentado no II Congresso Médico Estudantino, em Outubro de 1941, sob os auspicios do C. A. O. C. 


\section{ALTERAÇOES ELETROCARDIOGRAFICAS NA INSUFICIENCIA CORONARIANA}

As alterações eletrocardiográficas na insuficiência coronariana já eram conhecidas, de há muito, mas, tomaram novo rumo com os trabalhos anátomo-patológicos de BÜCHNER. Este autor demonstrou o substrato anatômico desse processo. Ele descreveu; nos indivíduos mortos, após uma angina de peito, certos focos de necrose disseminados no miocárdio. São as necroses hipoxtêmicas, que aparecem apenas nos casos em que o indivíduo ainda resiste algumas horas após as crises (BÜNGELER). BÜCHNER fez várias experiências sobre a falta aguda de oxigênio no miocárdio, pela injeção de pitressina; esta substância provoca o espasmo das coronárias e, em consequência, determina a interrupção súbita da corrente sanguínea ao coração. Outros pesquisadores conseguiram mostrar, no acme do espasmo provocado pela pitressina, um complexo ventricular monofásico deformado.

$\mathrm{Na}$ patologia humana, a não ser os casos de enfarte, esses estados tão agudos, com graves perturbações do miocárdio, são muito raros. Mais frequentes, são os casos de pacientes com pequeno grau de insuficiência coronariana. Foram feitas, então, experiências em câmeras de descompressão (Liechti, Opitz e TilmanN), em que o grau de carência de oxigênio é pequeno, obtendo-se traçados idênticos aos demonstrados nas experiências com a pitressina (GoldENBERG e Rothberger, Dietrich). Havia assim uma depressão do segmento ST abaixo da linha isoelétrica. Nos indivíduos sensiveis, consegue-se, de fato, provocar acessos anginosos, colocando-os em câmaras de descompressão; são de notar, nesse sentido, principalmente os trabalhos de Rotschild e Kissin, nos Estados Unidos, e de Schwieck e DieTRICH, na Alemanha.

Acompanhando as depressões do espaço ST aparecem, nesses processos, inversões da onda $T$, principalmente em $\mathrm{D}_{1}$ e $\mathrm{D}_{2}$.

Observações posteriores vieram mostrar que todas essas deformações são reversiveis, voltando o eletrocardiograma á normalidade, mais ou menos rapidamente.

Procurou-se, depois (BÜCHNER), a possivel relação entre as alterações eletrocardiográficas e a necrose hipoxêmica do miocárdio. Verificou-se que, essa necrose aparece muitas horas após o estado de hipoxemia aguda, - pelo menos 7 horas (BüNGELER) - num tempo, portanto, em que o traçado já voltou inteiramente à normalidade. As necroses tardias, surgidas na insuficiência coronariana, não podem, pois, ser a causa das alterações eletrocardiográficas. Estas, dependem, provavelmente, das perturbações metabólicas momentâneas, consequentes à falta súbita de oxigênio. Isto, leva a uma modificação dos fenômenos de condução na substância contratil e, portanto, a alterações da tensão elétrica do miocárdio, que são registradas no eletrocardiograma.

As necroses hipoxêmicas não produzem, pois, alterações eletrocardiográficas, mas são, juntamente com estas, a consequência da mesma causa, isto é, da insuficiência coronariana (BÜCHNER e vON LUCADOU). 


\section{ALTERAÇŐES ELETROCARDIOGRÁFICAS NO ENFARTE DO MIOCÁRDIO}

Iniciaremos este capítulo cơm o estudo das três derivações clássicas e, em seguida, focalizaremos as toráxicas.

As alterações do segmento ST e da onda T chamaram, sempre a atenção dos investigadores. Assim é, que foram observadas:

1 - A ação do calor e do frio sobre o ventrículo esquerdo, principalmente na face anterior, aumentando a amplitude de $\mathrm{T}$ ou tornando-o negativo é pontudo; efeitos opostos eram obtidos, se os agentes atuavam sobre o ventrículo direito.

2 - A ação do nitrato de prata, injetado diretamente na base do ventrículo direito, determinando onda $\mathrm{T}$ negativa, ou no ápice do ventrículo esquerdo, levando a um exagero dessa mesma onda (EPPINGER e Roth BERGER, 1909).

3 - A ação de traumatismos sobre o coração de rã, nas vizinhanças da ponta, produzindo elevação do espaço ST (SAmojloff, 1910).

4 - A ação da ligadura sobre o ramo septal da artéria interventricular anterior do cão, tornando negativa a onda $\mathrm{T}$ (KAHN, 1911).

Embora, em 1914, Rotschild e Oppenheimer já tivessem descrito uma diminuição da amplitude das ondas nas perturbações da irrigação cardíaca, os trabalhos verdadeiramente dirigidos sobre as coronárias ápareceram, em 1918, com FRED M. Smith. Este autor, interessado em saber quais as alterações eletrocardiográficas nas tromboses, fez uma série de experiências, em cães, ligando os vários ramos: das artérias coronárias. Observou que, logo após a ligadura de um dos principais ramos da artéria coronária esquerda, a onda $T$ se tornava mais alta e, em ąlguns casos, igualava ou excedia a altura da onda R. Às vezes, todo o segmento ST era comprometido e se originava do ramo descendente da onda $\mathrm{R}$, bem acima da linha isoelétrica. Dentro de 24 horas, a onda $\mathrm{T}$ se tornava negativa numa, duas ou mesmo nas três derivações. A forma ponteaguda do $T$ negativo ou mesmo do $\mathrm{T}$ positivo que surgia mais tarde, era caracteristica. A extensão e a duração da negatividade da onda $\mathrm{T}$ variavam, em geral, com o tamanho do enfarte; a amplitude, porem, ia diminuindo progressivamente até que, do $6 .^{\circ}$ ao $8 .^{\circ}$ dia, ou mais cedo, a onda $\mathrm{T}$ se tornava positiva em $\mathrm{D}_{3}$ e, mais tarde, tambem, em $\mathrm{D}_{1}$ e $\mathrm{D}_{\varepsilon}$. Podia acontecer tambem que $\mathrm{T}$ se tornava positivo primeiro em $\dot{\mathrm{D}}_{\mathbf{1}}$ e depois em $D_{2}$ e $D_{3}$. Da $2 .^{a}$ à $4 .^{a}$ semana, observava-se um $T$ positivo em todas as derivações ou, pelo menos, em duas. Neste estádio, podia associar-se uma redução no complexo QRS.

Esses trabalhos de Sмiтн, foram confirmados por vários observadores, que acentuaram, principalmente, os seguintes aspectos:

1 - O deśnivelamento do espaço ST.

2 - A direção assumida por ST, nos estádios precoces do enfarte do miocárdio. 
O primeiro caso publicado, de anomalias eletrocardiográficas produzidas pelo enfarte, no homem, foi o descrito pelo dr. JAMES B. Herrick, em 1919. O traçado, obtido 15 dias após o acidente coronariano, mostrou a onda $T$ negativa em $D_{1}$ e $D_{2}$. Em novo traçado, 10 dias depois, a onda $\mathrm{T}$ era menos negativa. Outro eletrocardiograma, obtido alguns meses mais tarde, apresentava notavel redução do complexo QRS. A aclusão da artéria coronária foi verificada à necrópsia.

Um grande progresso foi realizado no ano seguinte, 1920, quando PARDEE descreveu, num eletrocardiograma obtido 2 horas após um ataque de forte dor precordial, uma alteração que se caracterizava pelo desnivelamento d'o segmento $S T$ e pela inversão $d a$ onda $T$, que se apresentava pontuda. 'E' a chamada onda monofásica de PARDEE, que assume, em geral, o seguinte aspecto:

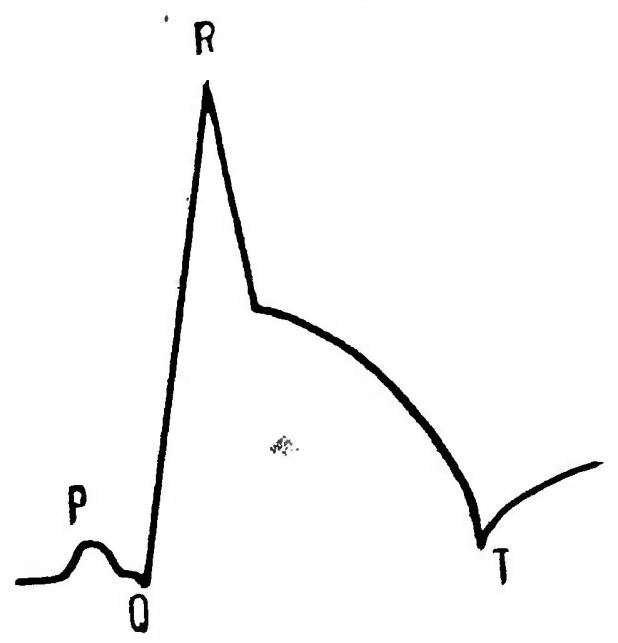

FIG. 1

Com a evolução do processo observou, ainda PARDEe, que o desnivelamento de ST desaparecia, progressivamente, ficando o traçado, ao fim de algum tempo, com a seguinte forma:

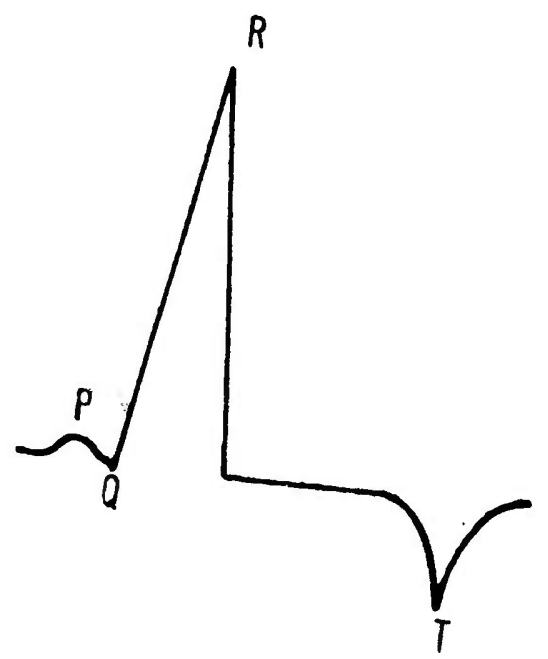

FIG. 2 
no qual se nota a onda T invertida e pontuda. E' a chamada onda $T$ coronariana de PARDEE.

Essas aquisições só foram completadas, mais tarde, em 1928, com os trabalhos de PARKINSON e BEDFord. Estes autores, foram dos primeiros a estudar minuciosamente a evolução das anomalias eletrocardiográficas no enfarte do miocárdio. Suas pesquisas foram baseadas no exame cuidadoso de 28 casos, com um diagnóstico comprovado. Concluiram que, eletrocardiogramas obtidos na primeira ou mesmo na segunda semana, mostram, geralmente, desnivelamento do segmento RT ou. ST, o primeiro originando-se da onda $\mathrm{R}$ a niveis variaveis acima da linha isoelétrica e or segundo aproximadamente à mesma distância abaixo da linha de base. O aspecto dessa deflexão desviada é variavel: pode ser relativamente achatada, redonda ou terminando em ápice. A amplitude é, geralmente, maior nos traçados que mostram QRS alto. Frequentemente, as alterações são mais evidentes em $\mathrm{D}_{1}$ e em $\mathrm{D}_{3}$ e, em geral, assumem direção oposta nessas derivações. Em seguida ao desnivelamento de $\mathrm{ST}$, a onda $\mathrm{T}$ tornar-se-á negativa em $D_{1}$ ou $D_{3}$ e oposta, respectivamente, em $D_{3}$ a $\mathrm{D}_{1}$, com ápice ponteagudo. Foram, então, descritos dois tipos de eletrocardiograma:

1) O tipo $T_{1}$, que se caracteriza por apresentar, em $D_{1}$, um desnivelamento plus (para cima da linha básica) do segmento ST e a onda $\mathrm{T}$ negativa e pontuda. $\mathrm{Em} \mathrm{D}_{3}$ há um desnivelamento minus de ST com $\mathrm{T}$ positivo e tambem pontudo:

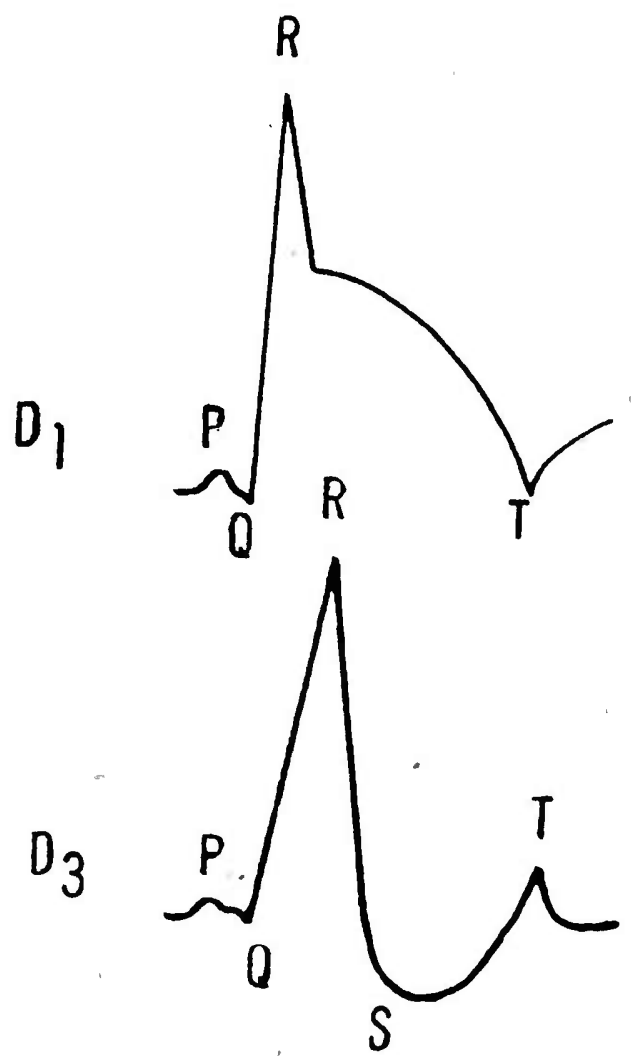

FIG. 3 


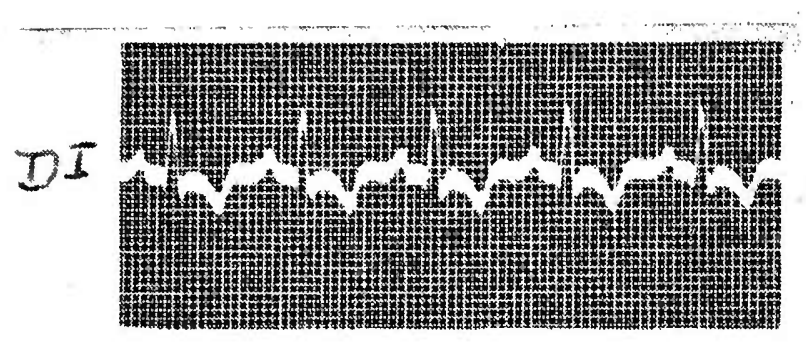

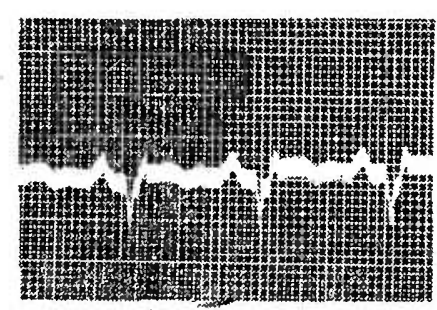

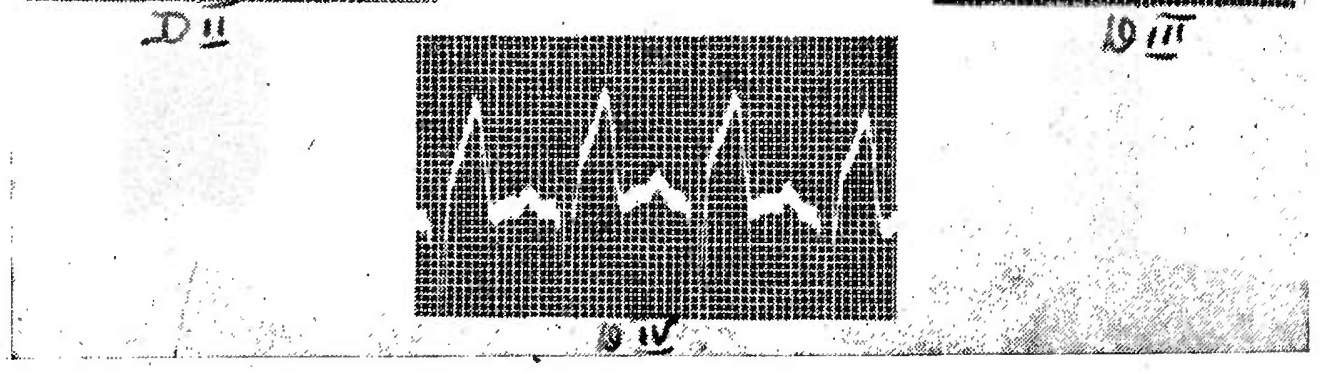

Figura 4

Enfarte, tipo $T_{1}$. Notem as anomalias de $S T$ e de $T$ em $D_{1}$ e $D_{3}$.

2) $O$ tipo $T_{3}$, que apresenta em $\mathrm{D}_{1}$ um desnivelamento minus ido segmento ST com um $\mathrm{T}$ positivo e pontudo. $\mathrm{Em} \mathrm{D}_{3}$, um desnivelamento plus de ST com a onda T negativa e pontuda: (Figs. 5 e 6).

Considerando apenas $\mathrm{D}_{1}$ e $\mathrm{D}_{3}$, podemos dizer que, no $1 .^{\circ}$ tipo, há uma convergência de $\mathrm{T}$ e $\mathrm{ST}$, que se opõem pelas concavidades, ao passo que, no $2 .^{\circ}$ há uma divergência dos mesmos acidentes, que se opõem pelas convexidardes.

Essas alteraçổes são notadas, em geral, na primeira semana, mas podem persistir por muito tempo.

Mais tarde, vai se processando o desaparecimento do desnivel de ST. Ao fim da $2 .^{\mathrm{a}}$ ou $3 .^{\mathrm{a}}$ semana, as anomalias que permanecem são, principalmente, as de $T$. Os tipos $T_{1}$ e $T_{3}$ de PArkinson e BEDFORD assumem, então, as seguintes formas: (Fig. 7).

Ao cabo de 6 meses, pode haver uma volta ao normal. Em alguns casos, porem, a onda $T$ fica, permanentemente, negativa.

Passados alguns anos, vários pesquisadores notaram que uma onda $Q$ profunda, mais evidente em $\mathrm{D}_{3}$, frequentemente se relacionava com o enfarte do miocárdio. Essa onda $Q$ profunda foi, depois, atribuida a uma lesão do septo. Wilson, MACLEOD; BARKer, JoHnsTON e Klastermeyer, em 1932, investigaram a relação entre esse achado gráfico e as alterações do segmento ST e da onda T. Obser- 

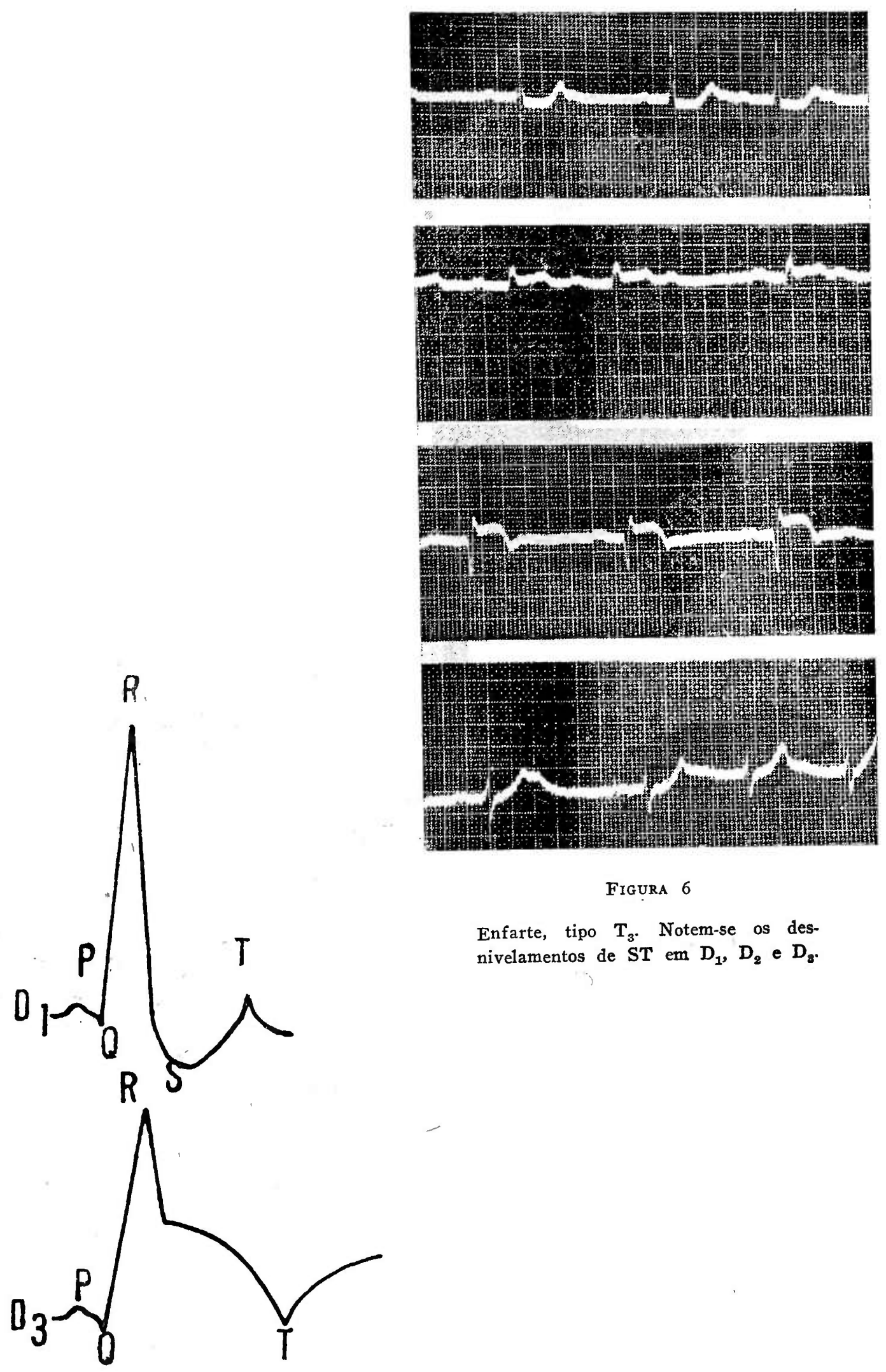

Figura 6

Enfarte, tipo $T_{3}$. Notem-se os desnivelamentos de $S T$ em $D_{1}, D_{2} \in D_{s}$.

Fic. 5 


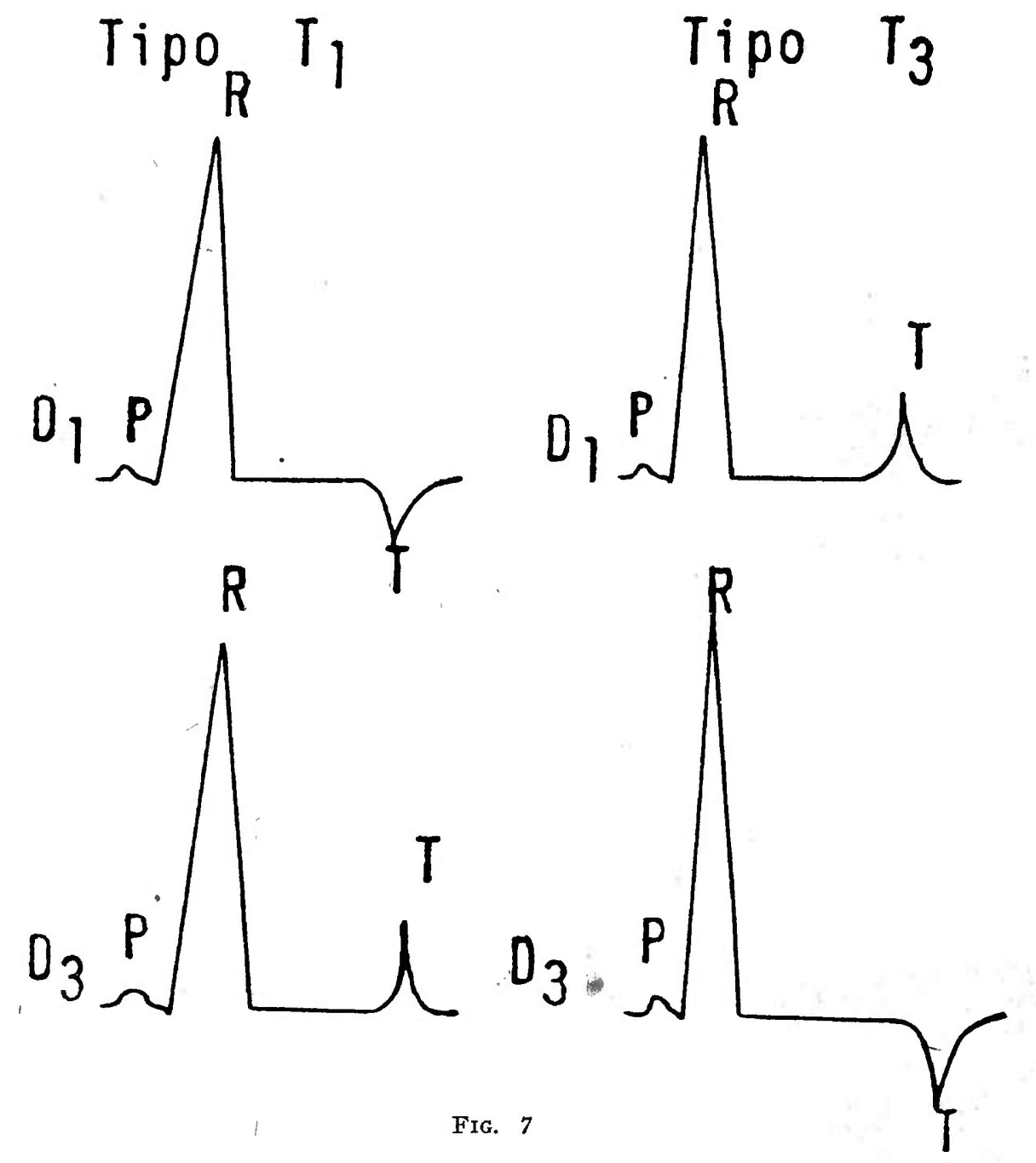

varam, que, no tipo $T_{1}$, de PARKINSON e BEDFORD, há, frequentemente, um $Q$ evidente em $D_{1}$ e que, no tipo $T_{3}$, há uma grande onda $Q$ em $D_{2}$ e $D_{3}$. Essas anomalias foram, então, associadas aos dois tipos de PARKINSON e BEDFORD, de modo que os processos passaram a ser denominados " $Q_{1} T_{1}$ " e " $Q_{3} T_{3}$ ". A onda $Q$ é, em geral, mais persistente que as modificações do espaço ST e da onda $T$. Ela pode ser util no diagnóstico do enfarte, na ausência de outros sinais.

PARDEE só considera como profunda, a onda $Q$, apresentando uma amplitude igual a, pelo menos $25 \%$ ida deflexão principal.

Naturalmente, como essa onda soi aparecer, com certa frequência, em vários estados que não os enfartes, procurou-se um carater distintivo destes casos.

Assim, Videla, em 1939, procuron distinguir a onda $Q$ profunda da lesão miocárdica, da que aparece em certos casos de elevação do diafragma, como na gravidez, na ascite, no tumor do abdomen, etc. Chegou, deste modo, à conclusão de que, se na inspiração profunda, $Q$ sofrer uma redução de mais de $50 \%$ da amplitude de $\mathrm{R}$, ela dependerá de outras causas e não de um enfarte do miocárdio. Se a redução for menor, então teremos uma alteração suspeita. 
Vários autores tém chamado a atenção para a possibilidade de um aumento da onda $\mathrm{P}$, nos casos de enfarte. Do mesmo modo, o espaço QT porde se apresentar aumentado. Como, porem, trata-se de anomalias de pequeno valor diagnóstico, não iremos discutí-las mais minuciosamente.

Muito recentemente, em 1941, Master e colaboradores descreveram um novo modelo de alterações eletrocardiográficas. E' a chamado tipo $T_{n}$, no qual encontramos a onda $T$ invertida em todas as derivaçễes.

Em resumo:

Todo o eletrocardiograma pode alterar-se, no enfarte do miocárdio. As anomalias mais importantes para o diagnóstico são, porem, as do complexo ventricular. No princípio, o desnivelamento do - segmento ST é o sinal mais importante. Mas, ele desaparece, em geral, dentro de alguns dias, sendo substituido pelas anomalias, menos características, da onda $\mathrm{T}$. Geralmente, o sentido assumido por ST em $\mathrm{D}_{1}$ é oposto ao assumido em $\mathrm{D}_{3}$ e, em ambas as derivações, pode ser para cima ou para baixo, produzindo os dois tipos comuns de traçados. O sentido da onda $\mathrm{T}$, porem, é contrário ao do segmento $\mathrm{ST}$, de modo que, um desnivelamento plus de $\mathrm{ST}$, em $\mathrm{D}_{1}$, é seguido de $\mathrm{T}$ negativo e vice-versa. A onda $\mathrm{T}$ é, ordinariamente, pontuda e vai sofrendo uma redução progressiva nos primeiros dias do enfarte até que, finalmente, estaciona. Com o tempo, esse desvio da onda $T$ pode desaparecer ou então permanècer em $D_{1}$ ou $D_{3}$. Essas alterações são, geralmente, acompanhadas de uma onda $Q$ profunda em $D_{1}$ ou em $D_{2}$ e $D_{3}$. Essa. onda $Q$ pode desaparecer, mas, muitas vezes, é o sinal mais persistente do enfarte do miocárdio.

Essas são as anomalias eletrocardiográficas mais ou menos específicas do enfarte. Naturalmente o traçado eletrocardiográfico é sempre um exame auxiliar. O quadro clínica conserva todo o seu valor. De fato, atualmente, há grande prudência, entre os cardiologistas, quanto à interpretação dos traçados, pois estes, embora sejam o elemento mais importante para o diagnóstico, ocasionam dúvidas, às vezes.

Com efeito, conhece-se a possibilidade de enfartes sem expressấo eletrocardiográficas, assim como a existência de anomalias quasi idênticas, em outros processos (enfartes pulmonares). Em todos os casos sempre é aconselhavel o estudo da evolução das curvas.

Ao lado daquelas alterações, podemos citar sinais de pequena especificidade, resultantes ou do próprio dano miocárdico, ou da localização do enfarte. Tais são, a redução da amplitude e a bizarra aparência do complexo QRS, o bloqueio de ramo, as extrassístoles, o bloqueio de arborização e a fibrilação auricular.

$$
* * *
$$

Durante os diferentes estudos, foram observados casos em que, ao diagnóstico clínico de enfarte do miocárdio, comprovados por necrópsia, não correspondiam sinais eletrocardiográficos. Para escla- 
recer esse fato, foram feitas várias experiências por FEIL, KATZ, Moore e SCOtt, em 1931, e por Wood e Wolferth, em 1933, mostrando que, se a obstrução aguda da artéria circunflexa do cão levava, quasi que invariavelmente, à produção, dentro de 2 minutos, do tipo de traçado patognomônico de lesão do miocárdio, o mesmo não acontecia com a oclusão da artéria interventricular anterior, que produzia insignificantes alterações no eletrocardiograma. Este achado sugeriu a idéia de que, nas condições da experiência, correntes elétriças da face anterior do coração não estavam sendo adequadamente conduzidas para os membros. Se um dos eletrodos 'fosse, porem, colocado sobre o coraçãa, apareciam prontamente as anomalias no segmento de ST. Estava, então, demonstrado o valor de uma derivação, em que se usasse um dos eletrodos sobre o precórdio.

Assim, essas derivações toráxicas $\left(D_{4}\right)$, já tentadas de há muito, e positivadas por Wolferth e Woon, embora não tivessem valor na determinação do eixo elétrico ântero-posterior, como se pretendia, eram, entretanto, sumamente valiosas para o reconhecimento de lesões miocárdicas. A forma normal de um traçado obtido com essas derivações toráxicas é a seguinte:

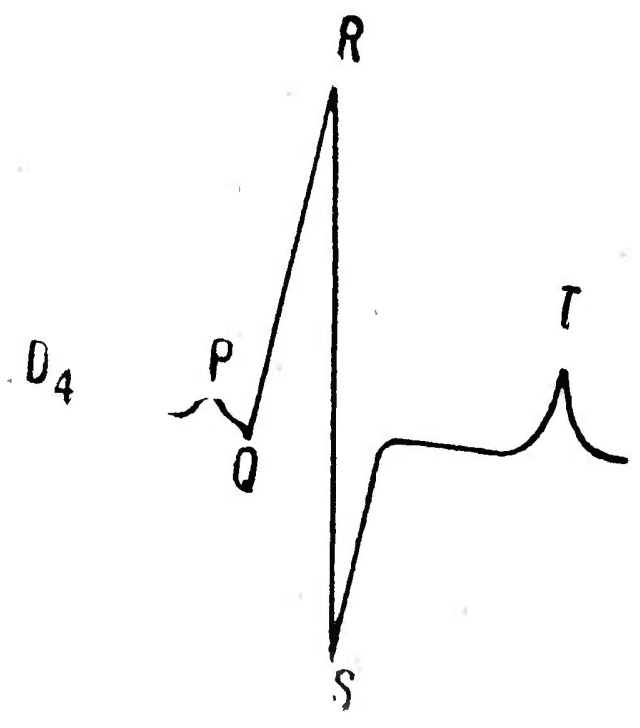

FIG. 8

Nos casos que correspondem ao tipo $T_{1}$ de Parkinson e BEDFORD, são as seguintes as anomalias:

1) Ausência de difasismo de QRS ou, apenas, uma diminuição da sua primeira onda positiva. Ambas estas anomalias não têm grande valor diagnóstico, sendo, entretanto, a primeira muito mais valiosa.

2). Desnivelamento plus do segmento ST. A onda T é inicialmente monofásica e, ao fim de certo tempo, se torna negativa e pontuda. (Figs. 9 e 10).

Os casos correspondentes ao tipo $\mathrm{T}_{3}$ de PARKinson e BEDFord apresentam alterações bem menos valiosas, assim um desnivelamento minus do espaço ST e uma onda $\mathrm{T}$ muito ampla. (Figs. $11 e^{\prime} 12$ ). 


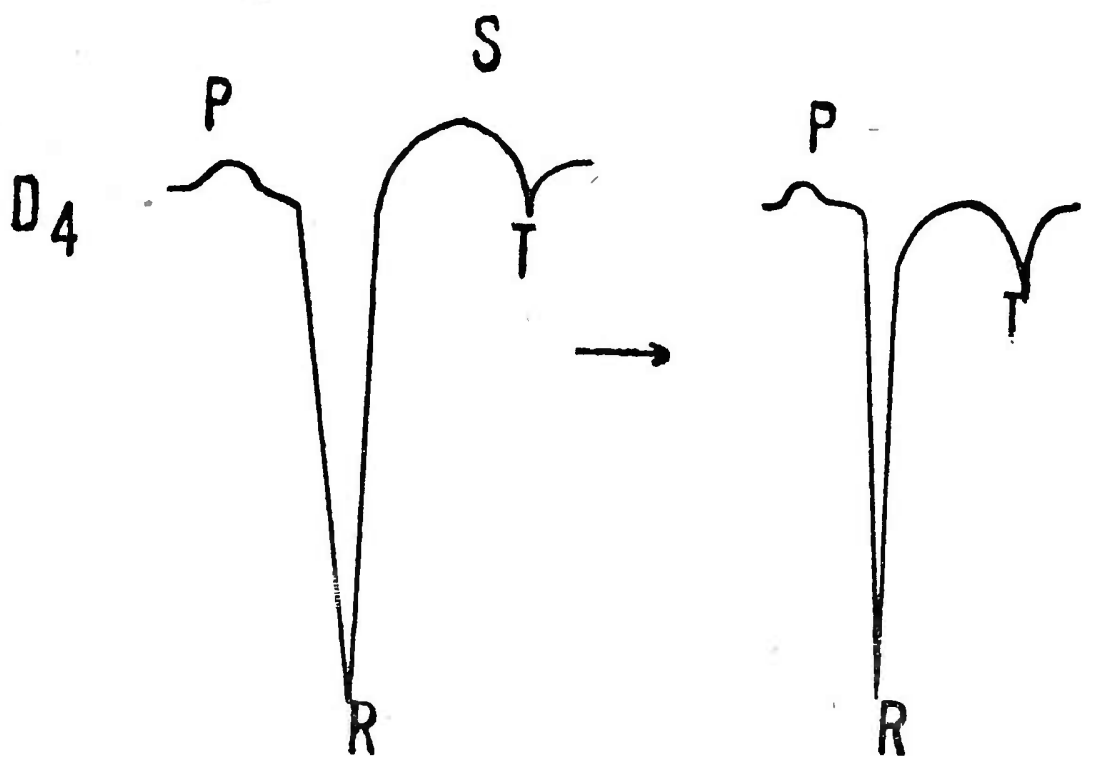

Fig. 9
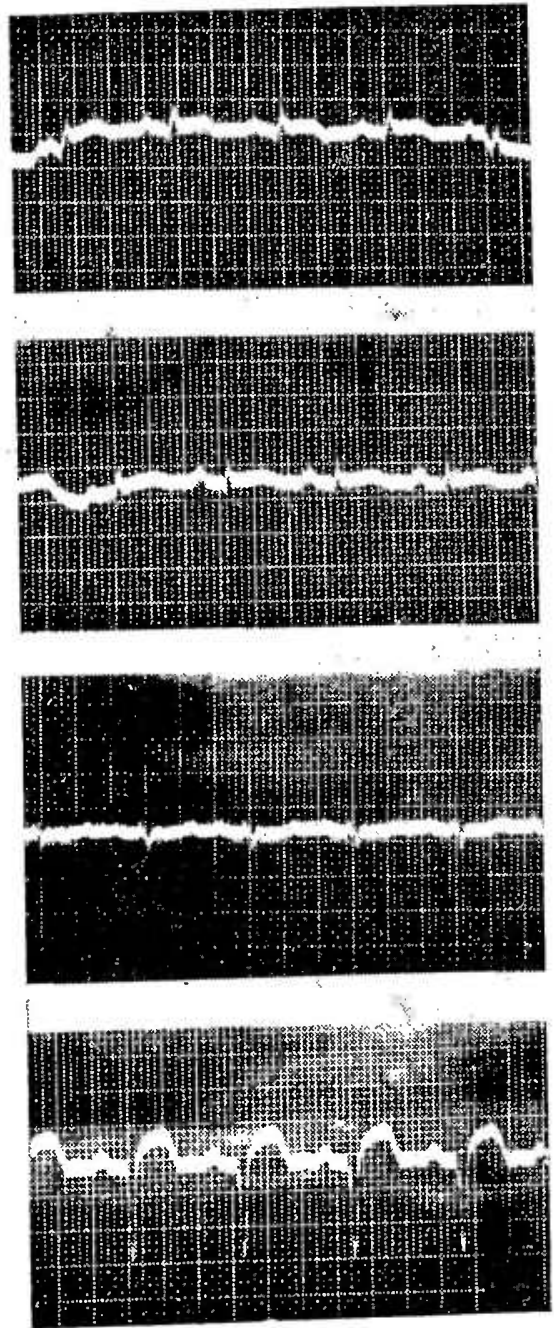

Figura 10

Enfarte, tipo $T_{1}$ Notem-se as anomalias em $D_{1}$ : ausència de difasismo de QRS, onda $T$ monofásica. Os desniQRS, onda de ST em $D_{1}$ e $D_{3}$ são velamentos de $S T$ em a pequena am. pouco acentuados, das ondas. 


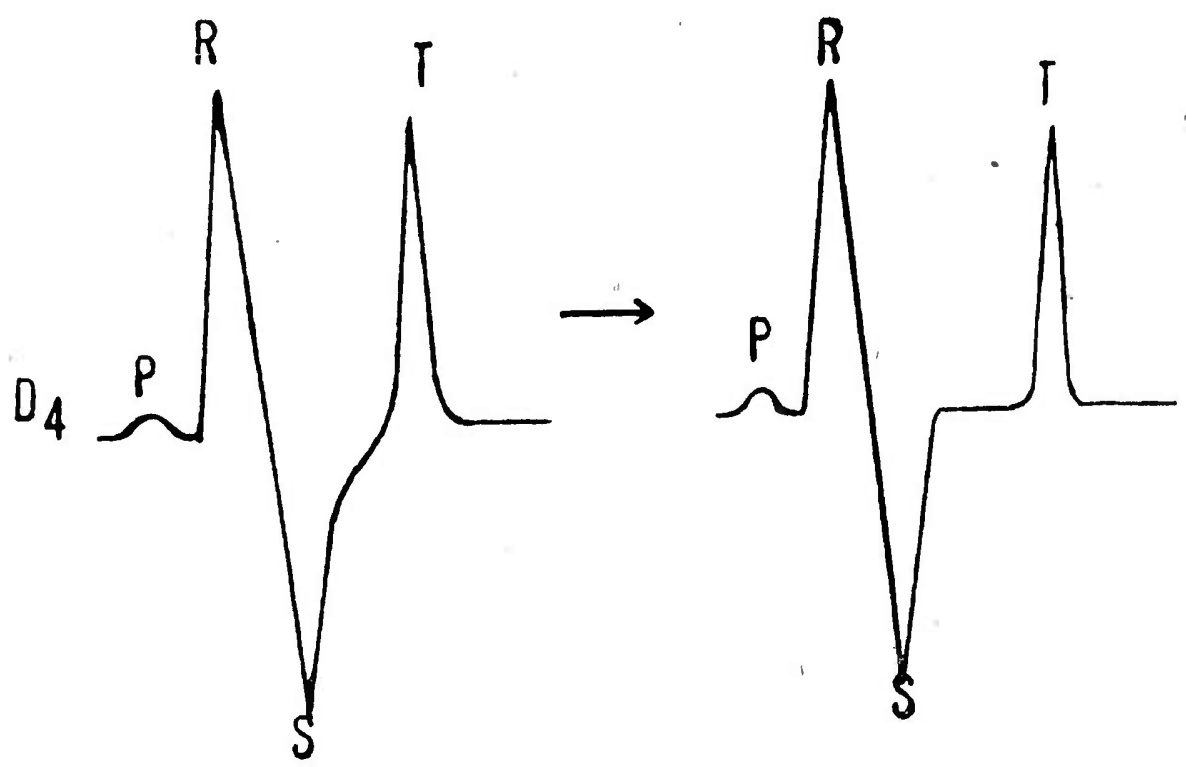

FiG. 11

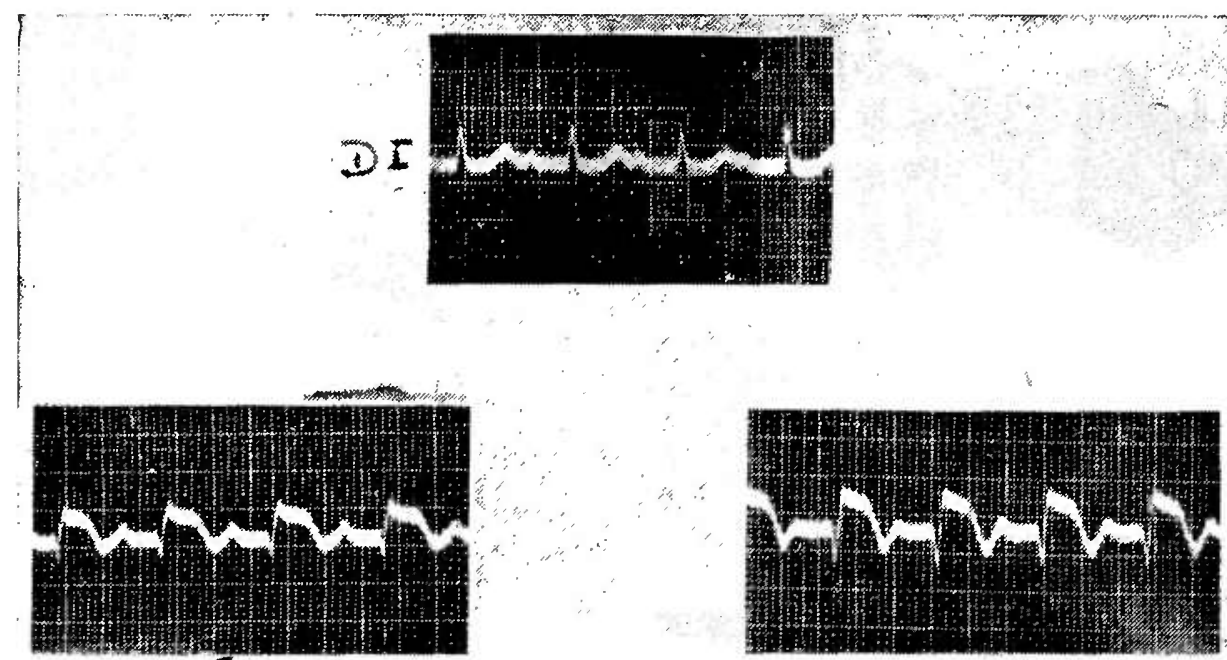

DII

骨

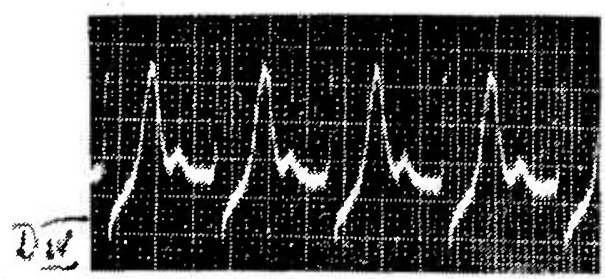

Figura 12

Enfarte, tipo $\mathrm{T}_{3}$. Notem-se as acentuadas anomalias de $\mathrm{ST}$, principalmente nítidas em $D_{3}$ e $D_{3}$. Em $D_{4}$, um desnivelamento minus de $S T$ com grande onda $T$ positiva.

\section{O PROBLEMA DA LOCALIZAÇÃO DO ENFARTE}

O problema da localização do enfarte pelas alterações eletrocardiográficas sempre prendeu a atenção dos pesquisadores. 
Após os trabalhos de Parkinson e Bedford, Barnes e WhitTEN; em 1929 e, depois BARNes e MANN, em 1932, estudaram cuidadosamente o assunto e concluiram pela estreita relação entre o tipo de traçado e a localização do enfarte. Estes trabalhos foram, mais tarde, confirmados por uns autores e criticados por outros. Entre estes últimos, estão Blumgart, Schlesinger e Davis que, em minucioso trabalho, publicado em 1940, citam condições sob as quais nunca se pode ter certeza no diagnóstico da sede do enfarte. Isto se dá, porque, com a esclerose progressiva das artérias coronárias, que aparece com a idade, há o desenvolvimento concomitante de una circulação colateral, que se torna apreciavel, conforme comprovações experimentais de vários autores (principalmente GreG, THORnton e MANTZ, em 1939). Aparecem, então anastomoses que ligam um ventrículo ao outro e, uma lesão nessas anastomoses, pode determinar um enfarte num ou noutro ventrículo. Em 125 autópsias, verificaram aqueles AA., várias vezes, enfartes por oclusão de uma artéria, no território anteriormente irrigado por outra.

Entretanto, não se esquecendo esse fato, a experiência demonstra que, na maioria dos casos, pode-se localizar, mais ou menos, a sede da lesão. Alguns AA., como por exemplo Bosco, pretenderam esquematizar demasiadamente o assunto, o que não é aconselhavel, na prática. Os AA. americanos nos dão uma orientação mais simples. Assim, o tipo $T_{1}$ de Parkinson e BeDFord indica, em geral, um enfarte da parede anterior do coração, principalmente do ventrículo esquerdo.

$\mathrm{O}$ tipo $T_{3}$, corresponde a um enfarte da parede posterior, principalmente do ventrículo direito.

A ond'a, $Q$ profunda indica, como já vimos, uma lesão do septo: $Q_{1}$ profundo estaria ligado a um enfarte anterior que alcançou tambem o septo e $Q_{3}$ profundo corresponderia a um enfarte posterior atingindo a mesma zona.

Alem desses, que são conhecidos por enfartes anterior (ou tipo ponta, dos argentinos), posterior (ou tipo base) e do septo, respectivamente, descreve-se ainda o enfarte lateral, traduzindo uma lesão na parte posterior da parede lateral esquerda.

O traçado desse tipo caracteriza-se por uma depressão do segmento $S T$ em $D_{1}, D_{2}$ e $D_{4}$, com inversão da onda $T$ nas mesmas derivações.

Quanto ao significado do tipo $\mathrm{T}_{\mathrm{n}}$, descrito por MASTER e colaboradores, ainda não podemos nos manifestar com segurança.

Todos os tipos mencionados correspondem aos casos em que há simples lęsão numa ou noutra parte dos ventrículos. Quando coexistem processos independentes, um na parede anterior e outro na parede posterior, o eletrocardiograma pode ser o tipo $T_{1}, T_{3}$ ou, mais comumente, misto. A espécie de curva obtida sob essa circunstância é aparentemente determinada pelo enfarte de mais recente origem. 


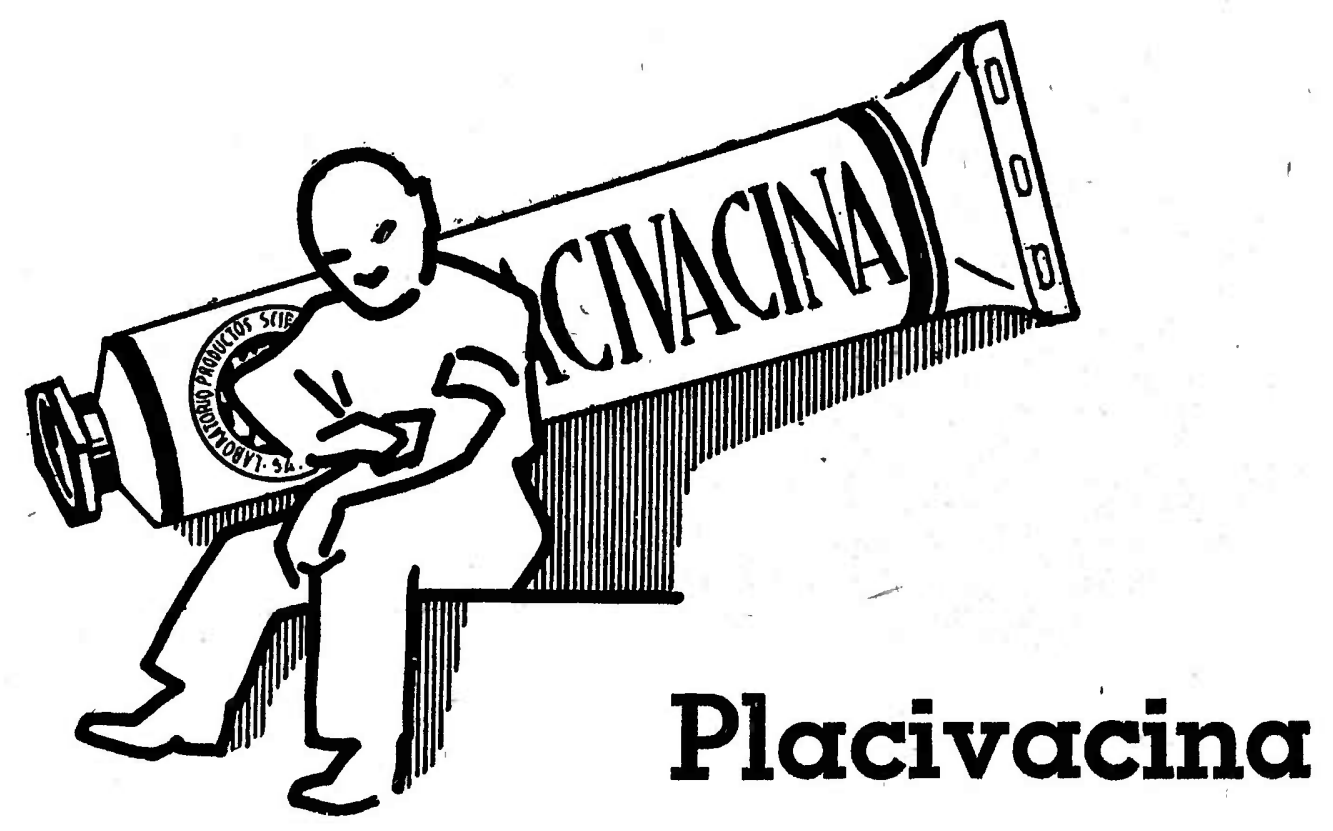

ANTI-PIÓGENA (anti=virus de Besredka)

CICATRIZANTE (Oleo de figado de bacalhau)

Laboratorio Torres - Rua Glicério, 429 - São Paulo

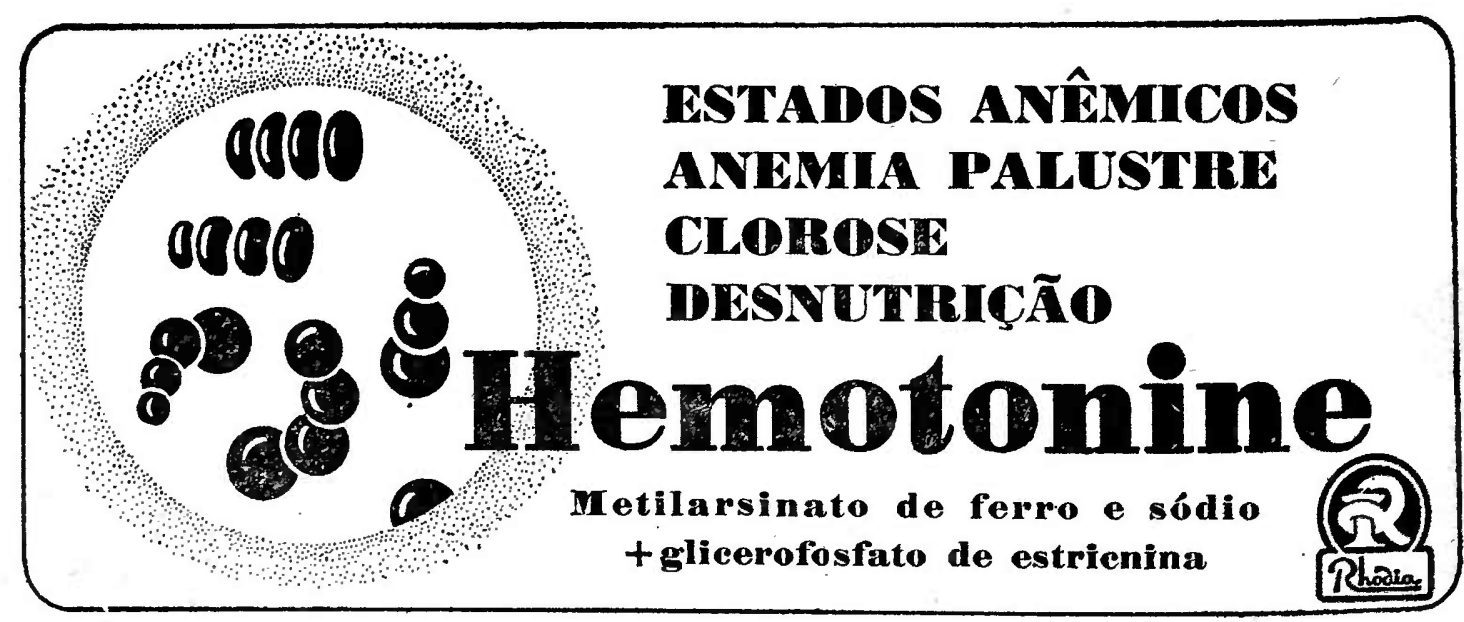

